\title{
The Guará campaign: A series of rocket-radar investigations of the Earth's upper atmosphere at the magnetic equator
}

\author{
R. F. Pfaff ${ }^{1}$, J. H. A. Sobral ${ }^{2}$, M. A. Abdu ${ }^{2}$, W. E. Swartz ${ }^{3}$, J. W. LaBelle ${ }^{4}$, \\ M. F. Larsen ${ }^{5}$, R. A. Goldberg ${ }^{1}$, F. J. Schmidlin ${ }^{1}$
}

The Guará Campaign consisted of a series of sounding rockets that were launched from August - October, 1994 at a new launch facility at Alcântara, Brazil, which is within one degree of the Earth's magnetic equator. The campaign consisted of focused scientific experiments designed to investigate the electrodynamics and irregularities in the equatorial ionosphere and mesosphere and to study their relationship with neutral upper atmosphere motions. In all, 13 large sounding rockets and 20 small meteorological rockets were launched as part of four different experiment groups designed to investigate: (1) the daytime equatorial electrojet, (2) very high altitude Spread-F processes, (3) sunset electrodynamics, and (4) middle atmosphere-thermosphere coupling at the equator. All of the experiments utilized ground-based scientific instruments including a VHF backscatter radar interferometer, magnetometers, ionosondes, and scintillation receivers. The project was a joint undertaking of the National Aeronautics and Space Administration (NASA) of the United States and the Instituto Nacional de Pesquisas Espacias (INPE) of Brazil. The project was named the Guará Campaign after a beautiful species of bird that is native to the equatorial region of Brazil.

\section{Site Location and Launch Facility}

The rocket investigations in the Guará Campaign required proximity to either the geomagnetic equator or the geographical equator. Both requirements are met by the launch range at Alcântara $\left(-44.37^{\circ} \mathrm{E}, 2.32^{\circ} \mathrm{S}\right)$ near the city of São Luis. An important feature of the Alcântara location is the local magnetic field geometry, which is distinguished for two reasons: (1) the dip equator undergoes its largest declination (nearly $32^{\circ}$ ) near this longitude, and (2) the magnetic equator undergoes its largest secular changes here. Figure 1(a) shows how the magnetic equator migrates northward at a rate of about $1^{\circ}$ of latitude every 5 years near the location, due to a westward shift of the South Atlantic magnetic anomaly. Although near Alcântara at $105 \mathrm{~km}$, the magnetic equator at higher altitudes shifts to greater distances towards the south, as shown in Figure 1(b).

The location of the Alcântara range on the Atlantic coast permits sounding rockets to be launched along azimuths that range from $-10^{\circ}$ to $75^{\circ}$ (measured from geographic north through east), and is ideal for launches directly along the local magnetic equator (azimuth of $58^{\circ}$ ). For safety reasons, the actual allowable azimuths vary somewhat depending on the performance

\footnotetext{
${ }_{1}^{1}$ NASA/Goddard Space Flight Center, Greenbelt, Maryland, USA

2 Instituto Nacional de Pesquisas Espacias, São José dos Campos, Brasil

3 Cornell University, Ithaca, New York, USA

4 Dartmouth College, Hanover, New Hampshire, USA

5 Clemson University, Clemson, South Carolina, USA

Copyright 1997 by the American Geophysical Union.
}

Paper number 97GL01534.

0094-8534/97/97GL-01534\$05.00 characteristics of a particular rocket vehicle. The science objective of each experiment dictated its specific launch azimuth.

The Alcântara facility currently includes a "Universal" launch rail and a blockhouse which are shown in Figure 2 along with a NASA Black Brant V sounding rocket ready to be launched into the electrojet. The range also includes operations, radar, telemetry, and meteorological buildings. NASA transported portable, temporary launchers to Alcântara to allow more than one rocket to be staged and/or launched simultaneously. The dual-launch capability was a key element of one experiment which required simultaneous vertical wind profiles separated in latitude (along the equator and $500 \mathrm{~km}$ to the north).

\section{Scientific Objectives and Experiment Descriptions}

The overall scientific objectives of the Guará campaign were to investigate the electrodynamics and irregularities in the ionosphere and mesosphere at the Earth's magnetic equator and, in some cases, to study their relationship to the neutral atmosphere and winds. To this end, four different investigations were undertaken which included in-situ experiments that measured various plasma and neutral parameters. All of the experiments used ground-based instruments including backscatter radars, magnetometers, and ionosondes. Brief descriptions of the four rocket investigations are given below.

Electrojet Experiments. Four rockets were launched into the daytime equatorial electrojet during a variety of geophysical conditions. This investigation was designed to address outstanding problems in electrojet physics [Pfaff, 1991] and were focused on two main scientific objectives: (1) to measure the complete DC electrodynamic parameters (DC electric field, current density, plasma number density) and relate these to the electrojet strength and formation, and (2) to perform a detailed study of the plasma instabilities in the equatorial electrojet including measurements of their wavenumber and phase velocity.

The electrojet payloads included instrumentation to measure the DC and wave electric fields, currents, plasma density, and instabilities associated with the electrojet. An attitude control system aligned the payload axis along the magnetic field direction so that the spin plane electric field double probes could measure both the horizontal and vertical instantaneous DC and wave electric fields. Two of the rockets included a pair of payloads launched in tandem.

The rocket payloads were launched along the equatorial electrojet which is a narrow corridor a few degrees wide which exists at altitudes of $100-110 \mathrm{~km}$. The eastward launch trajectory also enabled the westward-moving primary instabilities generated in the daytime electrojet to be Doppler-shifted to higher frequencies in the vehicle frame, facilitating their observation and interpretation. Details of the electrojet investigations and initial results are presented in papers by Pfaff et al. [this issue]. Three of the four electrojet rockets were successful; the fourth was launched into the strongest electrojet conditions, but the 

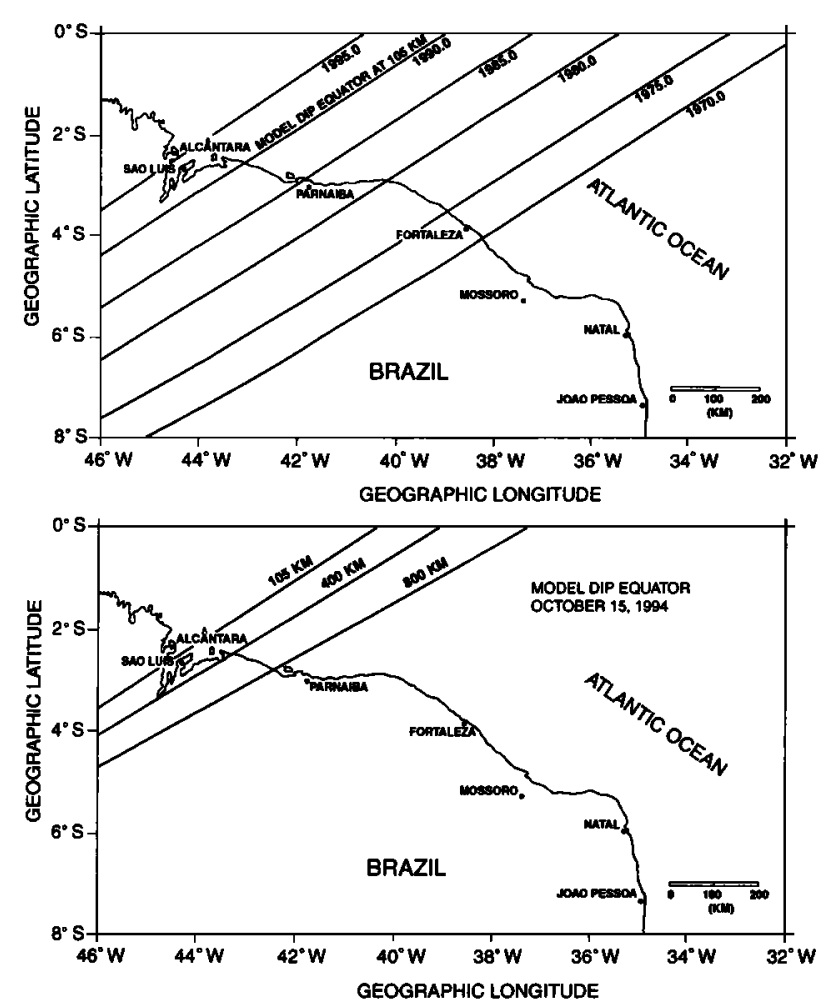

Figure 1. Coastline of Brazil showing the Alcântara launch site and the magnetic equator at $105 \mathrm{~km}$ for January 1, 1970, 1975, $1980,1985,1990$, and 1995 (upper) and the magnetic equator at $105 \mathrm{~km}, 500 \mathrm{~km}$, and $800 \mathrm{~km}$ for October 15, 1994 (lower).

instruments did not deploy due to a payload system failure. This was the only unsuccessful mission of the entire campaign.

Very-High Altitude Spread-F Experiment. The Guará campaign included a high-altitude rocket which probed ionospheric turbulence associated with equatorial spread $F$. The rocket reached an apogee of $957 \mathrm{~km}$ and detected spread F irregularities up to $822 \mathrm{~km}$, considerably higher than in previous such experiments. The principal goal of the experiment was to test MHD models of equatorial spread $F$ in conditions of low ionneutral collision frequency, for which theories predict distinct characteristics of the irregularity waveforms and spectra [e.g., Zargham and Seyler, 1987]. Measurement of the DC electric field up to $950 \mathrm{~km}$ was an additional goal.

Since measurements of electric field and electron density were critical to the experiment, several independent instruments provided these measurements: a plasma frequency probe, Langmuir probes, and a high-frequency capacitance probe for electron density; and two independent antenna systems for the electric field. As in the electrojet rockets, an attitude control system oriented the payload spin axis along the magnetic field to reliably measure the DC and wave electric fields.

The rocket was launched into active topside spread $F$ detected with the VHF portable radar, CUPRI, described below. LaBelle et al. [this issue] present measurements of irregularities $>1-\mathrm{km}$ and discuss their implications. Jahn et al. [this issue] present measurements of the associated DC electric field. Measurements of irregularities $<1-\mathrm{km}$ are the subject of a future publication.

Sunset Electrodynamics. The "Sunset Electrodynamics" experiment included a series of chemi-luminescent trimethyl aluminum (TMA) trails, as well as barium and strontium, released from the payloads at dusk. The chemical releases were used to measure the wind profiles from $90-180 \mathrm{~km}$ and the electric fields at apogee. Photographs of the chemical tracers were obtained from two ground sites and from a NASA aircraft. The experiment explored the mechanisms that set up enhanced electric fields at the magnetic equator near sunset and specifically investigated the role of the E-region neutral winds in this process, as discussed in theoretical studies [e.g., Farley et al., 1986].

Launches were carried out on each of two consecutive nights when the ionosonde measurements from São Luis indicated that the F-layer was rising. On each night, two Nike-Tomahawk sounding rockets were flown near-simultaneously from the Alcântara range. One rocket deployed a barium/strontium cloud near $250 \mathrm{~km}$ and a vertical TMA trail on the downleg close to the magnetic equator. The other rocket deployed a similar TMA trail approximately $500 \mathrm{~km}$ further north along the magnetic meridian. The motion of the barium cloud provided the $\mathbf{E} \times \mathbf{B}$ drift and thus the electric field. The wind profiles obtained from the trails were used to estimate the vertical and horizontal gradients of the neutral E-region flow, as well as the variation of the winds across the base of the magnetic field lines that map into the F-region at the equator. Details of the experiment and initial results are described by Larsen and Odom [this issue].

Mesosphere and Lower Thermosphere Equatorial Dynamics (MALTED). The MALTED program investigated the interaction between large scale planetary waves, medium scale gravity wave structure, and small-scale turbulence in the equatorial zone. A sequence of 4 sounding rocket payloads intermixed with 20 meteorological (MET) falling-sphere rockets were launched in a 10-day period. The sounding rocket payloads carried instruments to measure the electron density and smallscale turbulence in the upper mesosphere/lower thermosphere. At low altitudes $(<90 \mathrm{~km})$, the electron density may be used as a tracer of the neutral motions [Lehmacher et al, this issue]. From measurements of winds and temperatures, the MET payloads determined the variability of local small- and large-scale structures during the same period, allowing their role in turbulence production through wave breaking and other coupling processes to be determined. The MET payload consists of a passive inflatable falling sphere which is tracked by a precision radar to extract the required data [e.g., Schmidlin et al., 1986].

The MALTED launch sequence was coordinated with a global program called CADRE (Coupling and Dynamics of Regions Equatorial) to determine the influence of global wave dynamics

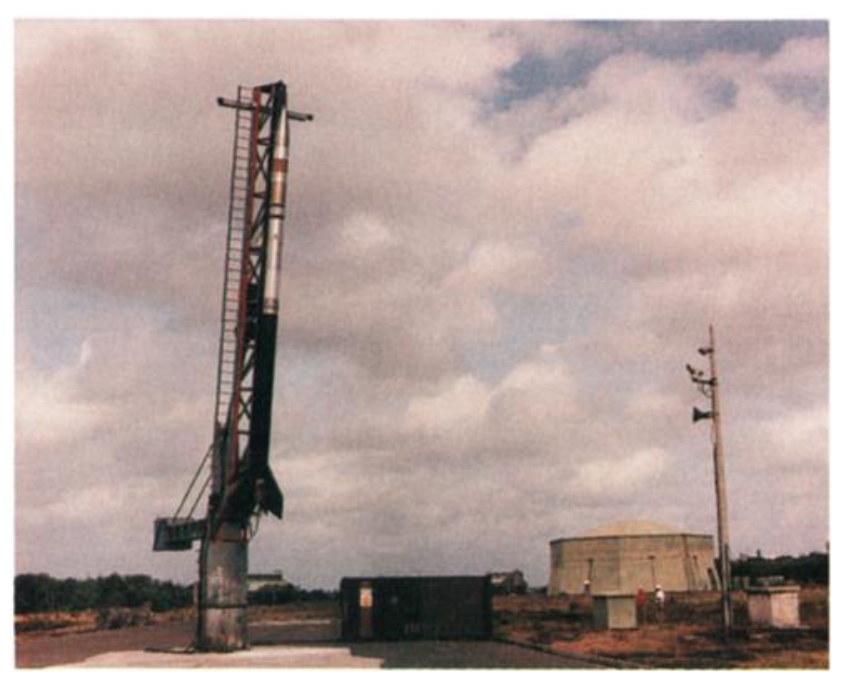

Figure 2. A photograph showing the blockhouse and a NASA sounding rocket ready for launch at the Alcântara facility. 
on the more localized structures. CADRE included measurements of global planetary and tidal wave structure through a network of ground-based observatories, aircraft, and the UARS satellite. Details of the experiment and initial results may be found in Goldberg et al., [1997].

\section{Ground-based Instruments}

All of the rocket experiments in the Guara campaign required simultaneous ground-based observations, both to determine the launch conditions and to provide contextual data needed to interpret the in-situ observations. Most of these instruments were set up either at the launch range at Alcântara or at the INPE Equatorial Geophysical Observatory which is permanently situated at the State University of Maranhão in São Luis. Other experiments were located at the INPE observing site at Cachoeira Paulista $\left(-45.0^{\circ} \mathrm{E}, 22.7^{\circ} \mathrm{S}\right)$, at the Jicamarca Radio Observatory in Peru $\left(-76.9^{\circ} \mathrm{E}, 12^{\circ} \mathrm{S}\right)$, and in Hawaii $\left(-160^{\circ} \mathrm{E}, 22^{\circ} \mathrm{N}\right)$. Most experiments required real-time data transmission and voice links to the Science Center located inside the Operations Center, where the launch decisions were made by the Principal Investigators.

Magnetometers. Ground-based magnetometer observations provided by INPE determined the existence of strong currents in the equatorial electrojet and were essential to the success of the electrojet rocket investigations. The instrument was situated at Alcântara and provided real-time, 3-axis magnetometer data with approximately $1 \mathrm{nT}$ resolution, updated once per minute. The sensor was buried $\sim 2 \mathrm{~m}$ in the ground to minimize offset variations due to thermal fluctuations. Figure 3 shows $\Delta H$ data for 36 continuous days during the Guara Campaign (N. Trivedi, personal communication, 1994). The large excursions near 11:00 A.M. L.T. each day are due to the electrojet current and illustrate the large day-to-day variations measured during this period.

The INPE magnetometer was part of a larger chain [e.g., Trivedi et al., this issue], which provided comprehensive

Alcántoro, Grazil

September 10 - Oetober 15, 1994

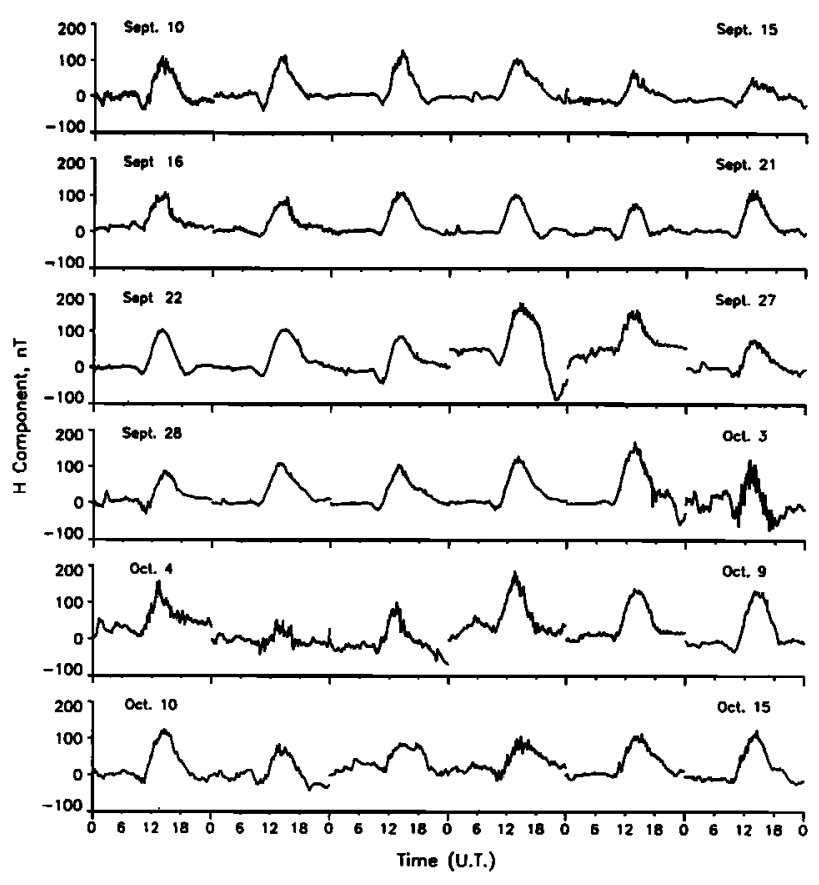

Figure 3. Ground-based magnetometer data showing the $\Delta \mathbf{H}$ component for 36 consecutive days during the Guará Campaign.

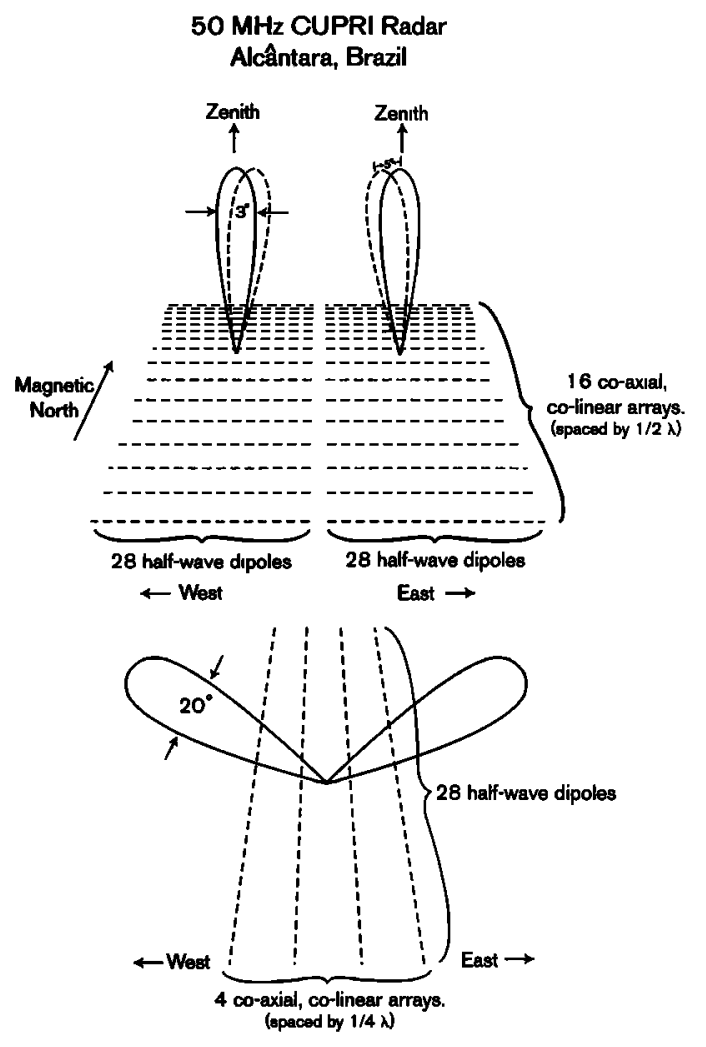

Figure 4. Diagrams of the CUPRI antenna systems at Alcântara. (upper) The east-west interferometer with either zenith-pointing beams or beams shifted towards magnetic north to be perpendicular to the magnetic field at $500 \mathrm{~km}$. (lower) An array set up to observe along the electrojet.

measurements for a longer time period as part of the International Equatorial Electrojet Year (IEEY). In addition to the permanent INPE magnetometer, two portable ground magnetometers with $1 \mathrm{~s}$ resolution were operated at Alcântara during the campaign, including ones from the NASA/Goddard Space Flight Center and the National Research Council of Canada. The Guará Campaign also contributed to the IEEY.

VHF backscatter radar. A key ground instrument for most of the rocket experiments was the Cornell University Portable Radar Interferometer (CUPRI), which was operated at Alcântara from August 20 - October 18, 1994. This instrument measures $46.9 \mathrm{MHz}$ radio wave echoes scattered by 3.2 -meter plasma density fluctuations in the ionosphere. Such echoes provide definitive indications of enhanced turbulence during strong electrojet and Spread-F conditions. The radar signature also provides evidence of the type of ionospheric instabilities present, and information concerning their speed and strength.

The CUPRI system set up at Alcântara included four different antenna arrays. As shown in Figure 4, two of the arrays consisted of 448 dipoles each and were vertically pointing to form a dual baseline interferometer oriented in the magnetic east-west direction. This dual beam radar was the principle tool for gathering the high resolution measurements of the electrojet [see papers by Swartz et al. this issue] and of Spread-F [LaBelle et al., this issue]. These arrays had a beamwidth of $3^{\circ}$ in the east-west direction and about $3.5^{\circ}$ in the north-south direction. A third array, also shown in Figure 4, was used for oblique observations over a range of $75^{\circ}$ [Swartz et al., this issue]. This array had a beamwidth of about $20^{\circ}$ in the vertical direction and $3^{\circ}$ in the north-south direction. A fourth array of 8 Yagi antennas created a north-south baseline for additional electrojet studies. 
At the start of the campaign, the CUPRI transmitter peak power was $19-20 \mathrm{~kW}$. Later, the AC voltage was raised to obtain peak powers of $50 \mathrm{~kW}$, which was important for the highest altitude (>1000 km) spread-F observations. At E-region heights, the dip equator was directly overhead so that a vertically pointing beam would be perpendicular to the magnetic field. However, as the dip equator shifts towards the south at higher altitudes (Figure 1b), the beam was tilted north to be perpendicular to the magnetic field for the spread-F experiments. This was achieved with special phasing cables. Raw data were recorded directly to magnetic tape, while echo power and selected Doppler spectra were displayed real-time as a function of range and time both in the CUPRI van and in the Science Center.

Ionosonde. During the Guará Campaign, the INPE ionosonde in São Luis operated continuously, providing real-time measurements of virtual heights of E- and F-layer features; from these, the zonal electric field is monitored. The ionosonde also detected the presence of electrojet and Spread-F irregularities and recorded data for later analysis as part of these experiments.

Scintillation Measurements. The INPE observatory at São Luis monitors amplitude and phase scintillations on a 136.38 $\mathrm{MHz}$ beacon transmitted from the GOES-1 satellite. GOES-1 lies to the west; the beacon transmission path intersects the Fregion (at $400 \mathrm{~km}$ altitude) approximately $300 \mathrm{~km}$ west of Săo Luis. Because the dominant F-region drift after sunset is eastward, the onset of scintillations often preceded radar detection of intense spread $\mathrm{F}$ overhead of Alcântara.

Dartmouth College obtained a dual-frequency Trimble4000SST GPS receiver and antenna from the UNAVCO consortium. This system was operated at Alcântara between October 1-20, 1994. With 15-second resolution, this system measured relative total electron content on lines-of-sight to eight satellites simultaneously. These data have been combined to produce images of the spread $F$ structure that agree in their basic features with CUPRI radar results [Musman et al., this issue].

Airglow receivers. Airglow was observed by the Utah State University portable optical imager set up at Alcântara, as well as the INPE airglow experiment at Cachoeria Paulista. These imagers provided information concerning spread-F and large scale ionospheric motions. Details of the Utah State airglow measurements are given by Taylor et al [this issue].

\section{Summary}

The motivation for the Guara Campaign was to understand several important electrical and neutral properties of the Earth's upper atmosphere at the magnetic equator. As discussed in subsequent articles in this issue, new aspects of the equatorial electrojet, Spread-F turbulence, the upper atmosphere at sunset, and gravity wave/turbulent interactions in the middle atmosphere were explored for the first time during the Guará Campaign. Each of these phenomena represent unique physical processes in space that only occur at or near the Earth's magnetic equator.
Some of the scientific highlights of the campaign include: -- first definitive observations of the polarization DC electric field in the daytime equatorial electrojet gathered with simultaneous observations of the current density;

-- first observations of the primary two-stream spectrum and phase velocities in the unstable equatorial electrojet;

-- first high altitude (>800 km) wave and DC electric field measurements in a spread-F plume simultaneously observed with a VHF backscatter radar;

-- first observations of the neutral wind gradients and DC electric fields associated with the pre-reversal enhancement of the electric field at the magnetic equator;

-- first measured evidence for gravity wave breaking in the equatorial mesosphere;

-- first dual radar observations of spread-F extended by several $1000 \mathrm{~km}$ in the east-west direction, using the Jicamarca radar in Peru and a radar in Brazil; and

-- confirmation of the east-west power asymmetry of oblique two-stream radar echoes and disproving of earlier theories.

Acknowledgments. The success of the Guara Campaign was due in large part to the efforts of many persons and organizations in both the United States and Brazil. In particular, we thank Mr. Marcio Barbosa and Mr. Roberto Pereira daCunha of INPE, Col. José Celso Cutrim Lauande and Eng. Fábio J. V. de Souza of the Alcântara Launch Center, and the US Embassy in Brazil. We also acknowledge the efforts of Mr. William Turner and Ms. Ingrid DeSilvestre of NASA's Office of International Relations. Finally, we salute the expert technical and logistical contributions from the NASA/Wallops Flight Facility, led by Mr. Jack Vieira, the NASA Campaign Manager, and Mr. Mark Cording, the NASA Campaign Engineer.

\section{References}

Farley, D. T., E. Bonelli, B. G. Fejer, and M. F. Larsen, The prereversal enhancement of the zonal electric field in the equatorial ionosphere, $L$ Geophys. Res., 21, 13723, 1986.

Goldberg, R. A., et al.., MALTED: a rocket/radar study of dynamics and turbulence in the equatorial mesopause region, L Geophys. Res, in press, 1997.

Pfaff, R. F., Rocket observations in the equatorial electrojet: Current status and critical problems, J. Atmos. Terr. Physics, 53, 709, 1991.

Schmidlin, F. J., Rocket techniques used to measure the middle atmosphere, Handbook for MAP, 19, edited by R. A. Goldberg, 1986.

Zargham, S., and C. E. Seyler, Collisional interchange instability, 1, numerical simulations of intermediate scale irregularities, L Geophys. Res., 22, 10073, 1987.

R. A. Goldberg, R. F. Pfaff, Jr., F. J. Schmidlin, NASA/Goddard Space Flight Center, Greenbelt, MD, 20771

M. A. Abdu, J. H. A. Sobral, Instituto Nacional de Pesquisas Espacias, Cx. Postal 515, São José dos Campos, Brasil

J. W. LaBelle, Dartmouth College, Hanover, NH, 03755

M. F. Larsen, Clemson University, SC, 29631

W. E. Swartz, School of Electrical Engineering, Cornell University, Ithaca, NY, 14853.

(Received: March 6, 1997; accepted: May 20, 1997.) 